\title{
STRATEGI GURU DALAM MEMPERTAHANKAN MINAT BELAJAR TARI PADA SISWA DI SEKOLAH DASAR
}

\author{
Elwis Nirmala Sari ${ }^{1}$, Gede Eka Puja Dyatmika ${ }^{2}$, Ni Putu Sasmika Dewi ${ }^{3}$ \\ 1,2,3 Institut Agama Hindu Negeri Gde Pudja Mataram \\ Coresponding author: Gede Eka Puja Dyatmika \\ Email: puja.dyatmika@stahn-gdepudja.ac.id
}

\begin{abstract}
The purpose of this study was to give an describe about the strategies of Hindu religious teachers in maintaining interest in learning dance extracurriculars for students at Elementary School 117 Cendana Putih II. This study uses a descriptive qualitative approach. Data were collected by non-participant observation, free-guided interviews and documentation. Based on the results of the study, it was found that the dance extracurricular learning process took place in three processes, namely first, the initial process of preparing the sound system, saying prayers, recording the number of students present, then warming up; second, the core process, namely dividing groups into each student, then doing exercises in turns in each group; and third, the final process is saying the closing prayer, finally tidying up the sound system. The obstacles faced by teachers in maintaining interest in learning dance extracurricular are: first, the lack of facilities and infrastructure; secondly the lack of trainers; third, the lack of make-up personnel during performances; fourth, students who are difficult to manage (naughty); fifth, lack of mastery of some dances. In an effort to overcome the existing obstacles, the strategies used by teachers in maintaining interest in learning dance extracurriculars are: first, practicing in the school yard and asking parents for help in completing the performance clothes; second, asking for help from students in training; third, asking parents for help in preparing students' performances; fourth, changing the way of learning; and fifth, providing training guidance specifically to sixth grade Students.
\end{abstract}

Keywords: Teacher Strategies, Interest in Learning, Dance

\begin{abstract}
Abstrak
Penelitian ini bertujuan untuk memberikan gambaran mengenai strategi guru agama Hindu dalam mempertahankan minat belajar ekstrakurikuler tari pada Siswa Sekolah Dasar Negeri 117 Cendana Putih II. Penelitian ini menggunakan pendekatan kualitatif deskriptif. Data dikumpulkan dengan observasi nonpartisipan, wawancara bebas terpimpin dan dokumentasi. Berdasarkan hasil penelitian diperoleh hasil bahwa proses pembelajaran ekstrakurikuler tari berlangsung dalam tiga proses, yaitu pertama, proses awal menyiapkan sound system, mengucapkan doa, mendata jumlah siswa yang hadir, kemudian melakukan pemanasan; kedua, proses inti yaitu membagi kelompok pada masing-masing siswa, kemudian melakukan latihan secara bergiliran pada masing-masing kelompok; dan ketiga, proses akhir yaitu mengucapkan doa penutup, terakhir merapikan sound system. Adapun kendala yang dihadapi guru dalam mempertahankan minat belajar ekstrakurikuler tari yaitu: pertama, kurangnya sarana dan prasarana; kedua kurangnya tenaga pelatih; ketiga, kurangnya tenaga perias pada saat pementasan; keempat, siswa yang sulit diatur (nakal); kelima, kurangnya penguasaan beberapa tarian. Sebagai upaya mengatasa kendala yang ada, strategi yang digunakan guru dalam mempertahankan minat belajar ekstrakurikuler tari yaitu: pertama, latihan di halaman sekolah dan meminta bantuan orang tua dalam melengkapi pakaian pementasan; kedua, meminta bantuan tenaga siswa dalam melatih; ketiga, meminta
\end{abstract}


bantuan orang tua dalam mempersiapkan pementasan siswa; keempat, mengganti cara belajar; dan kelima, memberikan bimbingan latihan secara khusus kepada siswa kelas enam.

Kata kunci : Strategi Guru, Minat Belajar, Tari

\section{PENDAHULUAN}

Pendidikan Agama Hindu merupakan salah satu bidang studi yang harus dipelajari sebagai persyaratan dalam menyelesaikan pendidikan pada semua jenjang pendidikan yang didesain dan diberikan kepada pelajar yang beragama Hindu dengan tujuan untuk mengembangkan keberagamaan mereka. Pendidikan berupaya mengembangkan jiwa keberagaman sehingga terlahir siswa yang moderat dan mau menerima perbedaan (Rudiarta, 2020). Pendidikan secara praktis tidak dapat dipisahkan dengan nilai-nilai budaya.

Guru bertugas membimbing siswa agar dapat memahami dan mengamalkan ajaran agama. Sehingga dalam membimbing siswa guru membutuhkan waktu seefektif mungkin, agar siswa mampu memahami dan mengerti tentang ajaran agama yang diberikan oleh pendidik di lingkungan sekolah. Pendidikan agama yang diterapkan di sekolah bukan hanya pendidikan formal tapi juga terdapat pendidikan non formal yang berkaitan dengan Agama Hindu yaitu kegiatan ekstrakurikuler tari.

Tujuan kegiatan ekstrakurikuler sesuai dengan tujuan yang tercantum dalam Permendiknas No.39 Tahun 2008 yaitu dapat mengembangkan potensi peserta didik secara optimal dan terpadu yang meliputi bakat, minat dan kreativitas, memantapkan kepribadian peserta didik untuk mewujudkan ketahanan sekolah sebagai lingkungan sehingga terhindar dari usaha dan pengaruh negatif dan bertentangan dengan tujuan pendidikan, mengaktualisasikan potensi peserta didik dalam pencapaian prestasi unggulan sesuai bakat dan minat.

$\begin{array}{ccc}\text { Penelitian Gotama dan } & \text { Kiswara } \\ \text { (2019) yang berjudul "Strategi }\end{array}$

Pembelajaran Seni Tari Pada Anak Disabilitas Pada Sanggar Sekar Dewata Desa Serongga Kecamatan Gianyar Kabupaten Gianyar" menunjukkan bahwa latihan tari begitu penting untuk diberikan kepada generasi muda termasuk bagi anak disabilitas. Dalam penelitian tersebut diungkapkan pentingnya penerapan strategi dalam pembelajaran seni tari, strategi yang digunakan, hingga implikasi yang ditimbulkan dari penerapan strategi tersebut.

Beranjak dari hasil penelitian Gotama dan Kiswara, peneliti melakukan penelitian serupa di Sekolah Dasar Negeri 117 Cendana Putih II, yang mana merupakan sekolah yang terletak di Desa Cendana Putih II Kecamatan Mappedeceng Kabupaten Luwu Utara Provinsi Sulawesi Selatan berkaitan dengan strategi yang digunakan dalam pembelajaran ekstra kurikuler tari. Sekolah ini memiliki berbagai kegiatan ekstrakuirikuler, kegiatan ekstrakurikuler yang berkaitan dengan Pendidikan Agama Hindu yang ada di SDN 117 Cendana Putih II adalah ekstrakurikuler Dharmagita dan ekstrakurikuler tari. Fokus peneli, dikarenakan dari sekian banyak kegiatan ekstrakurikuler yang ada, sebagian besar siswa memiliki minat yang cukup banyak pada ekstrakurikuler tari khususnya siswa yang beragama Hindu. Melalui latihan tari yang intensif diharapkan siswa menjadi lebih memahami makna dari setiap gerakan dalam tarian yang dilakukan (Lestari \& Gunada, 2021).

Meskipun kegiatan ekstrakurikuler tari memiliki minat yang cukup baik namun ada saja permasalahan yang dialami oleh seorang guru sebagai pendidik, guru mengalami beberapa kesulitan saat mengajar salah satunya yaitu, karena sempitnya ruangan yang 
digunakan untuk melakukan proses belajar mengajar membuat latihan kurang maksimal, dengan jumlah siswa yang cukup banyak membuat ruangan terlihat sempit, sehingga pada latihan akan terasa pengap dan panas. Namun meskipun ada saja permasalahan yang dihadapi tidak mengurangi minat dan semangat siswa untuk ikut belajar ekskul tari.

Berdasarkan ulasan di atas, beberapa permasalahan yang akan diulas pada tulisan ini mencakup proses pembelajaran ekstrakurikuler tari di Sekolah Dasar Negeri 117 Cendana Putih II Sulawesi Selatan, Kendala yang dihadapi guru Agama Hindu dalam mempertahankan minat belajar ekstrkurikuler tari pada siswa Sekolah Dasar Negeri 117 Cendana Putih II Sulawesi Selatan, dan strategi guru Agama Hindu dalam mempertahankan minat belajar ekstrakurikuler tari pada siswa Sekolah Dasar Negeri 117 Cendana Putih II Sulawesi Selatan. Adapun tujuan dari Penelitian ini adalah untuk memberikan gambaran mengenai strategi guru agama Hindu dalam mempertahankan minat belajar ekstrakurikuler tari pada Siswa Sekolah Dasar Negeri 117 Cendana Putih II.

\section{METODE}

Berdasarkan permasalahan yang dikemukakan, penelitian ini menggunakan metode kualitatif yaitu penelitian yang bersifat deskriptif yang bertujuan untuk memaparkan apa adanya dalam bentuk kata-kata, gambar bukan angka, kalaupun ada angka-angka sifatnya sebagai pendukung manakala ada yang kurang sempurna (Bungin, 2006).

Penelitian ini terfokus pada strategi guru Agama Hindu dalam mempertahankan minat belajar ekstrakurikuler tari yang dilihat dari hasil observasi, wawancara, dan dokumentasi. Dari data dan informasi yang peneliti peroleh, kemudian akan dianalisis agar diperoleh suatu penyimpulan yang menjadi hasil penelitian berupa saran atau rekomendasi baik untuk SD Negeri 117 Cendana Putih II. Dalam poses analisis data, keberadaan konsep serta landasan teori akan sangat bermanfaat bagi peneliti, dengan konsep peneliti akan dipermudah dalam memahami arah penelitian yang dilakukan.

\section{HASIL DAN PEMBAHASAN \\ Proses Pembelajaran Ekstrakurikuler Tari Sekolah Dasar Negeri 117 Cendana Putih II}

Pembelajaran Tari merupakan bagian dari pembelajaran seni dan budaya. Dalam kehidupan masyarakat Bali, kreativitas seni sangat erat kaitannya dengan upaya pembentukan karakter mulia. Kehalusan Budhi dapat terwujud melalui kreativitas seni (Armayani et al, 2021). Inilah yang menjadi sebuah alasan akan pentingnya pembelajaran Ekstrakurikuler Tari dimulai dari Sekolah Dasar.

Berdasarkan hasil observasi, wawancara dan dokumentasi yang telah peneliti lakukan diperoleh data mengenai proses pembelajaran yang dilakukan oleh guru Agama Hindu yaitu proses awal, proses inti dan proses akhir. Hal ini bersesuaian dengan tiga fase utama dalam proses belajar yang kerapkali diungkapkan oleh Brunner, yaitu tahap informasi, transformasi dan evaluasi (Rudiarta, 2020).

Proses Awal meliputi berbagai aktivitas yang dilakukan sebelum melakukan pelatihan tari. Kegiatan ini mencakup: guru menyiapkan sound system terlebih dahulu dalam memperlancar pembelajaran tari yang berlangsung dan guru juga melakukan doa bersama dengan siswa, setelah doa guru mengabsen siswa untuk mengetahui berapa jumlah dan mengetahui mana siswa yang rajin dan mana siswa yang malas. Lalu guru biasanya memberikan sedikit pemanasan untuk siswa agar pada saat latihan tidak terjadi sesuatu hal yang tidak diinginkan seperti apabila terjadi kesalahan dalam 
melakukan gerakan maka bisa menyebabkan tangan atau kaki terkilir, setelah melakukan sedikit pemanasan guru akan membagi kelompok untuk siswa siswi yang mengikuti latihan tari.

Setelah melalui proses awal, selanjutnya adalah proses inti. Setelah siswa dibagi ke dalam beberapa kelompok, guru akan memulai latihan dengan kelompok tari pendet yaitu tarian dasar terlebih dahulu. kemudian akan dilanjutkan dengan tarian-tarian dengan tingkat yang agak sulit. Dalam proses pembelajaran berlangsung kadang ada beberapa siswa yang kesulitan menangkap atau menghafal gerakan sehingga ditentukan dan dibentuklah kelompok agar mereka fokus pada satu tarian sebelum mempelajari tarian yang lebih sulit. Apabila sudah ditentukan masing-masing kelompok tari kemudian latihan akan dilakukan bergantian. Misalnya pada tahap pertama latihan dimulai dengan kelompok tari pendet.

Apabila proses inti sudah dilaksanakan, selanjutnya menuju pada proses akhir. Setelah melakukan proses pembelajaran ekstrakurikuler tari, biasanya pada akhir pembelajaran guru memberikan sedikit arahan kepada siswa, dan kemudian barulah kegiatan pembelajaran ditutup dengan melakukan doa bersama. Setelah doa dilakukan guru meminta bantuan kepada murit untuk merapikan kembali sound system yang digunakan dalam melakukan proses belajar mengajar.

Kendala Yang Dihadapi Oleh Guru Agama Hindu dalam Mempertahankan Minat Belajar Ekstrakurikuler Tari pada Siswa Sekolah Dasar Negeri 117 Cendana Putih II Sulawesi Selatan

Melaksanakan pembelajaran dengan baik merupakan tanggung jawab seorang guru dalam dunia pendidikan. Guru harus dikuatkan dengan pemahaman akan konsep mendesain pembelajaran agar bisa mencapai tujuan pembelajaran yang telah dicanangkan (Gunada, 2021). Desain pembelajaran tidak selamanya berjalan dengan baik, karena akan selalu ada kendala-kendala yang dialami. Demikian halnya dengan latihan kegiatan ekstrakurikuler tari di SDN 117 Cendana Putih II, ada beberapa kendala yang dihadapi oleh guru yang bersangkutan dalam mempertahankan minat belajar siswa di dalam proses pembelajaran ekstrakurikuler tari dipaparkan dalam bahasan berikut.

\section{Kurangnya Sarana dan Prasarana}

Dalam kegiatan ekstrakurikuler sarana dan prasarana adalah salah satu penunjang bagi anak-anak dalam mempertahankan minat belajar mereka. Keberadaan sarana dan prasarana sebagai media dan peralatan dalam latihan memang sangat menunjang efektivitas dari latihan yang dilakukan (Suseni et al., 2021). Hal ini dikarenakan dengan adanya sarana dan prasarana yang lengkap akan memberikan semangat tersendiri bagi siswa untuk mengikuti kegiatan ekskul yang ada di sekolah. Sarana dan prasarana adalah salah satu penunjang unuk memperlancar jalannya proses pembelajaran. Pada saat akan melakukan proses pembelajaran ekstrakurikuler tari guru Agama Hindu dan siswa kadang tidak nyaman pada saat akan latihan karena ruangan yang sempit dan pengap membuat latihan tari tidak maksimal dan pada saat akan melakukan pementasan pihak sekolah tidak memiliki pakaian tari yang lengkap membuat salah satu kendala yang dihadapi oleh guru Agama Hindu.

\section{Kurangnya Tenaga Pelatih}

Peran pelatih dalam kegiatan ekstra kurikuler Tari begitu vital. Keberadaan pelatih akan membuat para siswa melakukan pola latihan yang lebih terarah. Pelatih yang mampu menunjukkan sikap bersahabat dengan siswa (maitri) dan menebarkan cinta kasih yang merata (karuna) kepada siswanya akan membuat aktivitas latihan lebih efisien (Rudiarta, 2020). Dengan banyaknya siswa yang mengikuti kegiatan ekstrakurikuler tari dan 
tenaga guru untuk melatih sangat terbatas sehingga guru sedikit kewalahan dalam mengatur dan mengontrol siswa. Ekskul tari merupakan salah satu kegiatan yang membutuhkan tenaga pelatih lebih dari satu orang. Dalam latihan tari harus ada yang memberikan contoh di depan dan ada yang mengontrol dibelakang dengan begitu kegiatan proses pembelajaran bisa berjalan dengan lancar. Selain itu, kehadiran pelatih juga diharapkan dapat memberikan beberapa himbauan atau beberapa tips yang akan sangat bermanfaat dalam selama latihan (Pramana, 2020). Namun yang dihadapi oleh guru Agama Hindu karena kurangnya tenaga pelatih untuk membantu dalam mengajar hal tersebut membuat guru yang bersangkutan agak sedikit kesulitan dan kewalahan dalam mendidik siswa.

Kurangnya Tenaga Perias Saat Pementasan Tari

Ekstrakurikuler tari merupakan salah satu ekskul yang ribet dalam segi pakaian, berbeda dengan ekskul lain. Kenapa dikatakan sedikit menyusahkan karena apabila pada saat akan melakukan pementasan banyak alat pakaian, make up, bunga dll dibutuhkan. Pementasan dalam hal ini merupakan sebuah atraksi budaya berupaya menonjolkan nilai-nilai estetis dari sebuah gerak tari yang mampu menarik antusias orang di sekitar (Wirawan, 2019).

Pada saat menari bukan hanya dari segi gerak saja yang dilihat tetapi penampilan juga sangat penting untuk diperhatikan. Oleh karena itu guru yang bersangkutan dalam mengajar sekaligus bertanggung jawab dalam segi latihan, pakaian, dan pementasan membuat beliau sedikit kesulitan karena dalam mempersiapkan pakaian dan bertugas merias anak-anak dibutuhkan lebih banyak tenaga agar bisa cepat diselesaikan.

$\underline{\text { Siswa Yang Sulit Diatur (Nakal) }}$

Kegiatan ekstrakurikuler tari sesungguhnya merupakan bagian dari kegiatan pendidikan yang berupaya melaksanakan proses pembentukan karakter, fisik, motorik, sosial, emosional, moral, bahasa, kognitif, kreativitas dan Agama serta meletakkan dasar-dasar dalam kecakapan hidup (Wiguna \& Ekaningtyas, 2021).

Apabila point-point di atas dapat dibentuk maka proses pendidikan/latihan akan berjalan dengan sangat mudah. Akan tetapi nyatanya memutuhkan upaya yang sungguh-sungguh dari seorang guru untuk mencapai hal itu. Banyak Siswa yang sulit diatur pada saat melakukan proses pembelajaran termasuk dalam pelatihan tari. Hal ini tentunya akan menghambat proses pembelajaran yang diberikan oleh guru Agama Hindu. Dari hasil observasi peneliti melihat ketika guru mengajar atau mencontohkan didepan gerakan tari yang akan dilakukan tapi nampak siswa siswi terutama yang laki-laki terkadang tidak memperhatikan guru tetapi malah asik mengobrol atau menganggu teman yang sedang serius latihan.

Kurangnya Penguasaan dalam Beberapa $\underline{\text { Tarian }}$

Tari bali merupakan tari yang memiliki banyak gerakan dan memiliki banyak jenis tarian. Sebagai seorang pengajar harus bisa menguasai banyak tarian untuk melatih siswa-siswinya, dengan begitu proses pembelajaran tari akan berjalan menyenangkan siswa pun tidak merasa bosan apabila diajarkan banyak tarian oleh guru. Dari observasi yang peneliti lakukan dalam hasil wawancara langsung dengan guru Agama Hindu yang bertugas mengajar ekskul tari, beliau menyampaikan bahwa ada beberapa tarian yang kurang dikuasai oleh guru Agama Hindu. Hal tersebut menjadi salah satu kendala yang dihadapi dalam menghambat proses pembelajaran tari. 


\section{Strategi Guru Agama Hindu dalam Mempertahankan Minat Belajar Ekstrakurikuler Tari di Sekolah Dasar Negeri 117 Cendana Putih II Sulawesi Selatan}

Strategi dalam konteks proses bukan hanya implementasi dari semua rencana program pembelajaran yang telah dibuat, tetapi juga menyusun strategi yang akurat sebagai teknik untuk mengoptimalkan aktivitas anak didik dalam pembelajaran. Dalam latihan tari secara umum strategi latihan yang digunakan terdiri dari dua jenis, yaitu strategi langsung dan strategi interaktif. Dalam strategi langsung, guru secara intens memberikan arahan langsung kepada siswa berkaitan dengan teknik gerakan yang dilatih. Sedangkan strategi interaktif biasanya dilakukan dengan memberikan kesempatan kepada siswa untuk melakukan sharing, sehingga bisa mengungkap kesulitan yang dialami (Rani \& Putri, n.d.).

Strategi yang diterapkan oleh guru Agama Hindu dalam mempertahankan minat belajar/latihan tari pada siswa di SDN 117 Cendana Putih II tidak jauh berbeda dari strategi langsung dan interaktif, yaitu sebagai berikut.

Latihan Di Halaman Sekolah dan Meminta Bantuan kepada Orang Tua dalam Melengkapi Pakaian Pementasan

Sarana dan prasarana yang kurang memadai dalam proses pembelajaran tari bukan salah satu alasan bagi guru Agama Hindu untuk menghambat proses pembelajaran ekskul tari. Dari kendala yang dihadapi, guru memiliki strategi dalam menyelesaikan permasalahan tersebut yaitu karena ruangan kelas yang sempit dan pengap kadang membuat latihan tidak nyaman bagi siswa, strategi yang digunakan dalam mengatasi hal ini adalah guru yang mengajar ekskul tari melakukan proses pembelajaran tari di luar kelas yaitu tepatnya di halaman sekolah. Strategi yang digunakan untuk mengatasi kendala dalam segi pakaian pada saat akan melakukan pementasan yaitu, guru Agama Hindu biasanya meminta bantuan dari orang tua siswa untuk membantu melengkapi pakaian yang kurang, karena orang tua siswa merasa tidak terbebani dengan hal tersebut mereka pun siap membantu dalam segi pakaian. Keberhasilan dan proses pendidikan tidak terlepas dari peran serta stakeholder yang ada didalamnya, termasuk peran orang tua siswa (Yasa, 2021). Orang tua siswa di SDN 117 Cendana Putih II sangat mendukung dan merasa bangga anaknya mengikuti kegiatan ekskul tari oleh sebab itu mereka juga sangat berantusias dalam membantu mempersiapkan pakaian yang kurang dimiliki oleh pihak sekolah.

Meminta Bantuan Tenaga Siswa dalam Melatih

Karena kurangnya tenaga kepelatihan dalam melakukan proses pembelajaran tari guru Agama Hindu tidak bisa meminta bantuan teman guru lain untuk membantu karena yang mengajar di sekolah SDN 117 mayoritas beragama islam, dengan begitu strategi yang digunakan adalah dalam proses pembelajaran biasanya guru menyuruh siswa untuk menghafal tariannya terlebih dahulu meskipun gerakannya belum benar yang terpenting siswa menghafal tarian tersebut. Sehingga beliau hanya perlu untuk memperbaiki gerakan tangan, kaki, badan yang kurang tepat, strategi lain yang digunakan yaitu agar semua siswa dapat dikontrol dengan baik pada saat latihan biasanya guru meminta bantuan kepada siswa yang sudah hafal tarian yang akan dipelajari untuk mencontohkan di depan dengan begitu guru bisa memperbaiki gerakan-gerakannya.

Meminta Bantuan Orang Tua dalam Mempersiapkan Pementasan Siswa

Karena kurangnya tenaga bantuan dalam merias anak-anak guru meminta bantuan kepada orang tua siswa dalam menggunakan pakaian dan merias wajah. Karena riasan tari bali membutuhkan 
waktu yang cukup lama, orang tua siswa pun tidak keberatan dengan hal tersebut mereka malah merasa senang karena bisa membantu dalam kegiatan acara sekolah. Dengan begitu mereka bisa melihat secara langsung pementasan tari bali yang dilakukan oleh anak-anaknya. Sebagai seorang pendidik pasti akan mengalami kendala dalam melakukan proses pembelajaran dengan begitu sebagai seorang guru harus menyiapkan solusi atau strategi dalam menyelesaikannya sehingga proses pembelajaran akan berjalan lancar dan menyenangkan.

\section{Mengganti Cara Belajar}

Siswa yang sulit diatur memang biasa terjadi dalam melakukan proses belajar mengajar. Tidak semua anak memiliki karakter atau sifat yang sama. Dalam satu kelas pasti ada saja siswa yang sulit diatur atau suka menganggu temannya pada saat melakukan proses pembelajaran. Siswa yang kadang ribut dan suka mengganggu temannya ditempatkan di posisi depan dengan begitu mereka tidak akan menggangu dan bermain-main di belakang serta mereka akan fokus ikut dalam pembelajaran tari yang diberikan.

Memberikan Bimbingan Latihan Secara Khusus Kepada Siswa Kelas Enam

Pada saat melakukan proses pembelajaran guru yang bertugas mengajar ekskul tari bukan guru lulusan seni jadi beliau mengajar siswa dengan beberapa tarian yang memang sudah dikuasai, namun ada beberapa tarian yang kurang dikuasai oleh guru Agama Hindu oleh karena itu guru memberikan latihan khusus kepada siswa kelas enam, karena mereka dianggap siswa yang paling tua dan siswa yang lebih berpengalaman dari adik-adik kelas sehingga mereka dibimbing atau dilatih agar pada saat melakukan proses pembelajaran dapat membantu guru dalam melatih.

\section{PENUTUP \\ Simpulan}

Proses pembelajaran ekstra kurikuler tari di SDN 117 Cendana Putih II terdiri dari tiga proses yaitu: pertama, proses awal menyiapkan sound system, mengucapkan doa, mendata jumlah siswa yang hadir, kemudian melakukan pemanasan; kedua, proses inti yaitu membagi kelompok pada masing-masing siswa, kemudian melakukan latihan secara bergiliran pada masing-masing kelompok; ketiga, proses akhir yaitu mengucapkan doa penutup, terakhir merapikan sound system. Selain proses ada juga kendala yang dihadapi oleh guru Agama Hindu yaitu Pertama, kurangnya sarana dan prasarana; kedua kurangnya tenaga pelatih; ketiga, kurangnya tenaga merias pada saat pementasan; keempat, siswa yang sulit diatur (nakal); kelima, kurangnya penguasaan beberapa tarian. Adapun Strategi yang digunakan oleh guru Agama Hindu dalam mempertahankan minat belajar ekstrakurikuler tari pada siswa yaitu: Pertama, latihan di halaman sekolah dan meminta bantuan orang tua dalam melengkapi pakaian pementasan; kedua, meminta bantuan tenaga siswa dalam melatih; ketiga, meminta bantuan orang tua dalam mempersiapkan pementasan siswa; keempat, mengganti cara belajar; kelima, memberikan bimbingan latihan secara khusus kepada siswa kelas enam.

\section{Saran}

Tulisan ini masih memiliki banyak kekurangan dan kekeliruan. Besar harapan penulis, ke depannya tulisan ini bisa dijadikan referensi dalam pengembangan strategi dalam pembelajaran terkhusus dalam pembelajaran/latihan tari di sekolah. 


\section{DAFTAR PUSTAKA}

Armayani, N. M. R. T., Intaran, I. M., Andriani, I. G. A., \& Wirawan, I. W. A. (2021). Symbolic Representation Of Śiwa Națarāja In The Balinese Dance Creativity And Its Impact On Health Maintenance: A Literature Review. Kamaya: Jurnal Ilmu Agama, 4(1), 94-113.

Bungin, B. (2006). Sosiologi Komunikasi. Kencana Premada Media Group

Gotama, N. N. W. A., \& Kiswara, K. A. T. (2019). Strategi Pembelajaran Seni Tari pada Anak Disabilitas pada Sanggar Sekar Dewata Desa Serongga Kecamatan Gianyar Kabupaten Gianyar. WIDYANATYA, 1(2), 128-138.

Gunada, I. W. A. (2021). PENGUATAN KARAKTER MELALUI DESAIN PEMBELAJARAN

PENDIDIKAN AGAMA HINDU ( CHARACTER

STRENGTHENING THROUGH HINDU RELIGIOUS EDUCATION INSTRUCTIONAL DESIGN ). 12, 32-46.

Lestari, N. W. R., \& Gunada, I. W. A. (2021). Pelatihan Seni Tari Pada Siswa Pasraman Sebagai Bentuk Transformasi Kebudayaan. SELAPARANG Jurnal Pengabdian ..., 4(April), 280-285. http://journal.ummat.ac.id/index.ph p/jpmb/article/view/4428

Menteri Pendidikan Nasional. (2008). Permendiknas No. 39 Tahun 2008 tentang Pembinaan Kesiswaan. Mendiknas.

Pramana, I. B. K. Y. (2020). PERAN INSTRUKTUR YOGA DALAM MENTRANSFORMASI KESEHATAN DI LOMBOK YOGA CENTER KOTA MATARAM. MEDIA BINA ILMIAH, 14(9), 3171-3178.

Rani, D., \& Putri, E. (n.d.). STRATEGI GURU

DALAM PELAKSANAAN PEMBELAJARAN
EKSTRAKURIKULER SENI TARI DI SMP NEGERI 1 AMBULU JEMBER. 1.

Rudiarta, I. W. (2020). CATUR PARAMITA SEBAGAI PENDEKATAN LATIHAN YOGA ASANA DI STAHN GDE PUDJA MATARAM. MEDIA BINA ILMIAH, 14(11), 33453356.

Rudiarta, I. W. (2020). Implementasi Pendidikan Berbasis Hindu Dalam Membangun Harmoni Di Era Disrupsi Sosial. Prosiding STHD Klaten Jawa Tengah, 1(1), 39-50. https://prosiding.sthdjateng.ac.id/index.php/psthd/article /view/28

Rudiarta, I. W. (2020). Implikasi Latihan Yoga Asana Bagi Pembentukan Karakter Siswa Di Ashram Gandhi Puri Sevagram Klungkung. Jurnal Penelitian Agama Hindu. https://doi.org/10.25078/jpah.v4i1. 1314

Suseni, M., Arini, N. M., Putu, N., Dewi, S., Method, C., \& Motor, F. (2021). IMPLEMENTASI METODE KOLASE DALAM. 1.

Wiguna, I. B. A. A., \& Ekaningtyas, N. L. D. (2021). Strategi Orang Tua Dalam Mendampingi Anak Usia Dini Belajar Daring Di Rumah. Pratama Widya: Jurnal Pendidikan Anak Usia Dini, 6(1), 86-95. https://www.ejournal.ihdn.ac.id/ind ex.php/PW/issue/archive

Wirawan, I. W. A. (2019). Identifikasi Pendidikan Multikultural Dalam Festival Seni Budaya Pada Komunitas Sasak-Islam Dan BaliHindu Di Bayan, Kabupaten Lombok Utara. Widyacarya: Jurnal Pendidikan, Agama dan Budaya, 3(1), 89-100.

Yasa, I. M. A. (2021). Optimalisasi Pengabdian Masyarakat Pada Sekolah Paud Binaan. Selaparang: Jurnal Pengabdian Masyarakat Berkemajuan, 4(2), 179-187. 
https://e-journal.iahn-gdepudja.ac.id/index.php/PS

Padma Sari: Jurnal Ilmu Pendidikan

http://journal.ummat.ac.id/index.ph
Vol. 01, No. 01, Oktober 2021

p/jpmb/article/view/4387. 